\title{
Does body mass index early in pregnancy influence the risk of maternal anaemia? An observational study in Indonesian and Ghanaian women
}

Martina Mocking ${ }^{1 \dagger}$, Ary I. Savitri ${ }^{1 \dagger}$, Cuno S. P. M. Uiterwaal', Dwirani Amelia², Edward Antwi ${ }^{3}$, Mohammad Baharuddin², Diederick E. Grobbee ${ }^{1}$, Kerstin Klipstein-Grobusch ${ }^{1,4}$ and Joyce L. Browne ${ }^{1 *}$ (DD

\begin{abstract}
Background: Anaemia is common among pregnant women, especially in low- and middle-income countries (LMICS). While body mass index (BMI) relates to many risk factors for anaemia in pregnancy, little is known about the direct relation with anaemia itself. This is particularly relevant in Southeast Asia and Sub-Saharan Africa where the prevalence of anaemia in pregnancy and the associated adverse outcomes is among the highest worldwide. This study aimed to assess the association between early pregnancy BMI and anaemia at first antenatal care visit in Indonesian and Ghanaian women. In addition, the associations between early pregnancy anaemia and adverse birth outcomes was assessed.
\end{abstract}

Methods: Prospective cohort studies of women in early pregnancy were conducted in Jakarta, Indonesia ( $n=433$ ) and in Accra, Ghana ( $n=946)$, between 2012 and 2014. Linear regression analysis was used to assess relations between early pregnancy BMI and pregnancy haemoglobin levels at booking. Logistic regression analyses were used to assess associations between early pregnancy anaemia as defined by the World Health Organization (WHO) criteria and a composite of adverse birth outcomes including stillbirth, low birth weight and preterm birth.

Results: Indonesian women had lower BMl than Ghanaian women (23.0 vs $25.4 \mathrm{~kg} / \mathrm{m}^{2}, p<0.001$ ) and higher mean haemoglobin levels $(12.4 \mathrm{vs} 11.1 \mathrm{~g} / \mathrm{dL}, p<0.001)$, corresponding to anaemia prevalence of 10 and $44 \%$, respectively. Higher early pregnancy BMI was associated with higher haemoglobin levels in Indonesian $\left(0.054 \mathrm{~g} / \mathrm{dL} / \mathrm{kg} / \mathrm{m}^{2}, 95 \%\right.$ $\mathrm{Cl} 0.03$ to $0.08, p<0.001)$ and Ghanaian women $\left(0.044 \mathrm{~g} / \mathrm{dL} / \mathrm{kg} / \mathrm{m}^{2}, 0.02\right.$ to $\left.0.07, p<0.001\right)$. Accordingly, risk for anaemia decreased with higher early pregnancy BMI for Indonesians (adjusted OR 0.88, 0.81 to 0.97, $p=0.01$ ) and Ghanaians (adjusted OR 0.95, 0.92 to $0.98, p<0.001$ ). No association between anaemia and the composite of adverse birth outcomes was observed.

Conclusion: Higher BMI in early pregnancy is associated with higher haemoglobin levels at antenatal booking and with a reduced risk of anaemia in Indonesian and Ghanaian women.

Keywords: LMIC's, Early pregnancy BMI, Anaemia

\footnotetext{
* Correspondence: j.l.browne@umcutrecht.nl

${ }^{\dagger}$ Martina Mocking and Ary I. Savitri contributed equally to this work.

'Julius Global Health, Julius Center for Health Sciences and Primary Care,

University Medical Center Utrecht, Utrecht, The Netherlands

Full list of author information is available at the end of the article
}

(c) The Author(s). 2018 Open Access This article is distributed under the terms of the Creative Commons Attribution 4.0 International License (http://creativecommons.org/licenses/by/4.0/), which permits unrestricted use, distribution, and reproduction in any medium, provided you give appropriate credit to the original author(s) and the source, provide a link to the Creative Commons license, and indicate if changes were made. The Creative Commons Public Domain Dedication waiver (http://creativecommons.org/publicdomain/zero/1.0/) applies to the data made available in this article, unless otherwise stated. 


\section{Background}

Anaemia is a major public health problem affecting 1.62 billion people globally [1]. Notably, 32 million (38\%) pregnant women are anaemic, of whom 750,000 severely anaemic (haemoglobin level $<7.0 \mathrm{~g} / \mathrm{dL}$ ) [2]. In low- and middle-income countries (LMICs) maternal anaemia occurs in $43 \%$ of pregnant women, with the highest prevalence found in Southern Asian (52\%), Central African and West African countries (56\%) [3].

Anaemia in pregnancy, particularly in LMIC, is associated with lower socioeconomic status [1], young maternal age, low parity $[1,4,5]$, ethnicity $[6,7]$, being in the third trimester [4, 7-9], and having many children [1, 7, 9]. Causes include micronutrient deficiencies (including iron, vitamin B12, folic acid and vitamin A), parasitic infections (such as malaria, helminth, hookworm and schistosomiasis), HIV/AIDS, chronic inflammation and genetic haemoglobinopathies (e.g. thalassaemia) [1, 3, 10]. Anaemia in pregnancy is associated with increased perinatal and maternal mortality [11], and other adverse outcomes including low birth weight, preterm birth $[1,3,6,10,12]$ and reduced maternal productivity due to fatigue $[1,13]$.

There is a growing interest in the pre- and early pregnancy maternal physical condition, particularly body mass index (BMI), and its role in healthy pregnancy [14-17]. Underweight in (early) pregnancy is associated with preterm birth, low birthweight, miscarriage and having a small for gestational age baby [14, 18-20], whilst protecting against hypertensive disorders of pregnancy and gestational diabetes $[14,17,18]$. In contrast, maternal overweight and obesity are associated with higher risks for adverse obstetric and perinatal outcomes, including delivery complications, hypertensive disorders of pregnancy, gestational diabetes, macrosomia, and stillbirth [21-24].

In many South Asian and West and Central African countries, anaemia in pregnancy, persistent underweight and simultaneously increase in prevalence of overweight and obesity are common and potentially related health problems. A number of studies reported that low BMI increases the risk of anaemia in pregnancy $[8,14,18]$. However, these studies were limited by methodological choices such as uncertain anaemia cut-off levels or varying gestational ages at which haemoglobin level was determined [25]. Using cohorts from Indonesia and Ghana, in the present study we assessed whether early pregnancy $\mathrm{BMI}$ is related to anaemia at first antenatal booking.

\section{Methods}

\section{Study design and study population}

This study was conducted using data from two prospective cohort studies from Indonesia and Ghana, previously described in detail $[26,27]$.

\section{Indonesian cohort}

From February 2013 to October 2014 pregnant women were recruited during their first antenatal care visit at the private mother-child health Budi Kemuliaan Hospital and its branch Budi Kemuliaan Petojo. There were no particular inclusion criteria and routine antenatal blood tests were performed at booking in all recruited women with gestational age lower than 18 weeks. After enrolment, women were seen during their subsequent antenatal care (ANC) visits and followed up until delivery. Information was obtained about women's socioeconomic status (level of education and current employment), current pregnancy (last menstrual period to determine gestational age and early pregnancy weight) and obstetrical history (gravidity). To estimate exposure to secondhand smoking, the spouse's smoking status was documented.

\section{Ghanaian cohort}

From July 2012 to March 2014, 1010 pregnant women from the Accra Metropolis in Ghana were enrolled at the Ghana Health Services facilities Maamobi General Hospital and Ridge Hospital's outpatient clinic. Women were eligible for participation if they were less than 17 weeks pregnant, 18 years or older and did not have a history of hypertension or hypertension at booking. Information was obtained on socio-demographic characteristics, socioeconomic status (level of education and economic activity) and health status including obstetrical status and history. Women were followed up until six weeks postpartum. Information about smoking was not recorded given the low prevalence of smoking in this population $(<0.3 \%)[28]$.

\section{Data set, entry and validation}

For both cohorts, analyses were restricted to women with available early pregnancy BMI and early pregnancy blood test results. Missing data was not imputed because of low occurrence and complete cases were analysed.

\section{Predictors}

Early pregnancy BMI was calculated as weight (in kilograms) divided by the square of height (in meters) [2], in which Indonesian women's weight was based on the self-reported pre-pregnancy weight. For Ghanaian women, maternal weight at booking was used as early pregnancy weight.

\section{Outcomes}

\section{Primary outcome}

Haemoglobin concentration and anaemia status were measured as primary outcomes. Anaemia was defined as a haemoglobin concentration below $11.0 \mathrm{~g} / \mathrm{dL}$, according to the WHO's definition for anaemia in pregnancy [29].

Haemoglobin levels were measured in accordance with routine antenatal care standards by local laboratories. 


\section{Secondary outcome}

As a secondary outcome, a composite of adverse birth outcomes was created and included stillbirth, low birth weight and preterm birth. Stillbirth was defined as the death of the foetus after 24 weeks of gestation and low birth weight was defined as birth weight $<2.500$ g. Preterm birth was defined as birth at less than 37 weeks of gestation. Gestational age was determined by last menstrual period (in Indonesian cohort) or by ultrasound at or before the first antenatal care visit (in Ghanaian cohort) [30].

\section{Confounders}

A priori, the following variables were considered as possible confounders of the relationship between early pregnancy BMI and haemoglobin level or anaemia: maternal age, gravidity, employment status and highest completed education [1, 12, 17, 24]. Employment status was classified as not working, working in a formal job or working in a non-formal job (trader, nanny, cleaning service, etc). Education was categorized into low (including uneducated, completed elementary school, and completed junior high school), intermediate (completed senior high school), and high (university degree or professional education).

Furthermore, secondhand smoking exposure was considered as potential confounder $[2,18,29]$. and was adjusted for in the Indonesian cohort. Comorbidities associated with anaemia, including sickle cell disease, glucose-6-phosphate dehydrogenase (G6PD) deficiency and malaria, were also considered as confounders $[31,32]$ and were adjusted for in the Ghanaian cohort.

\section{Data analysis}

Women's baseline characteristics were tabulated by their early pregnancy BMI. Due to major dissimilarities between Ghanaian and Indonesian BMI distribution, we used tertiles instead of World Health Organisation (WHO) BMI categories. Moreover, controversy exists on applying the existing WHO BMI categories for Asian populations, in which previous studies suggested lower cut-offs [33, 34]. Differences between tertiles of early pregnancy BMI were statistically tested using one-way ANOVA or Kruskal-Wallis for continuous and Pearson's Chi-square or Fisher's exact test for categorical variables, where appropriate.

Linear regression analysis was used with haemoglobin concentration as the dependent and early pregnancy $\mathrm{BMI}$ as the independent continuous variable. Logistic regression analysis was used with anaemia (yes/no) as the dependent and early pregnancy BMI as the independent continuous variable. For both types of analysis, we also separately evaluated the effect of weight and height on the outcomes. Logistic regression was also used to assess relations between anaemia and composite adverse birth outcomes. Results are expressed as linear regression coefficients or odds ratios and $95 \%$ confidence intervals. A $p$-value $<0.05$ was considered statistically significant. All analyses were performed using IBM SPSS Statistics (version 21.0 for Windows) and were reported in accordance to STROBE Statement [35].

\section{Study approval}

For the Indonesian cohort ethical approval was granted by the Institutional Review Board of Budi Kemuliaan Hospital. For the Ghanaian study population approval was obtained from Ghana Health Services Ethical Review Committee (GHS-ERC 07-9-11). In both cohorts, participating women provided written or thumbprint informed consent prior to study enrolment.

\section{Results}

Of the Indonesian cohort, 433 women were included in the present analysis and 946 women from the Ghanaian cohort. Table 1 shows the baseline characteristics of the women according to their early pregnancy BMI tertiles, Additional file 1: Table S1 provides an overview of missing data.

The BMI of the first, second, and third tertile ranged between 12.5 to $20.6,20.6$ to 24.3 and 24.4 to $39.2 \mathrm{~kg} / \mathrm{m}^{2}$ for Indonesian women and 15.4 to 23.1, 23.1 to 27.0 and 27.1 to $42.3 \mathrm{~kg} / \mathrm{m}^{2}$ for Ghanaian women. In both cohorts, women in the first tertile were significantly younger and more likely to be nulliparous than those in the second and third tertiles. Indonesian women in the first tertile had more often a formal job than those in the second and third tertile, with unemployment being more common in the third tertile.

\section{Early pregnancy BMI, haemoglobin level and anaemia}

Mean BMI and the estimated prevalence of anaemia early in pregnancy were lower in Indonesian than in Ghanaian women (23.0 vs $25.4 \mathrm{~kg} / \mathrm{m}^{2}$ and $10.4 \%$ vs $44.1 \%$, respectively). Table 2 presents the association between early pregnancy weight, height and BMI, and risk of anaemia at first antenatal care visit. Haemoglobin concentration increased significantly with higher BMI in Indonesian $(0.05 \mathrm{~g} / \mathrm{dL} / \mathrm{kg} /$ $\mathrm{m}^{2} ; 95 \%$ CI $\left.0.03,0.08\right)$ and Ghanaian women $(0.04 \mathrm{~g} / \mathrm{dL} /$ $\mathrm{kg} / \mathrm{m} 2 ; 95 \%$ CI $0.02,0.07)$. Associations were unaltered by adjustment for potential confounders. As Fig. 1a and b illustrate, women with higher early pregnancy BMI tended to have higher haemoglobin levels. Correspondingly, higher early pregnancy BMI was associated with lower odds for anaemia at antenatal care booking in Indonesian (adjusted OR 0.88; 95\% CI 0.81, 0.97) and Ghanaian women (adjusted OR 0.95; 95\% CI 0.92, 0.98).

Higher early pregnancy weight was found related with higher haemoglobin levels and lower risks for anaemia in both cohorts, but height was not. 
Table 1 Baseline characteristics of the study populations categorized by early pregnancy BMI tertiles

\begin{tabular}{|c|c|c|c|c|c|c|c|c|}
\hline \multirow[t]{2}{*}{ Early pregnancy BMI } & \multicolumn{3}{|c|}{ Indonesian cohort } & \multirow[t]{2}{*}{$P$ value } & \multicolumn{3}{|c|}{ Ghanaian cohort } & \multirow[t]{2}{*}{$P$ value } \\
\hline & $\begin{array}{l}\text { Lower tertile } \\
(n=145)\end{array}$ & $\begin{array}{l}\text { Middle tertile } \\
(n=143)\end{array}$ & $\begin{array}{l}\text { Upper tertile } \\
(n=148)\end{array}$ & & $\begin{array}{l}\text { Lower tertile } \\
(n=334)\end{array}$ & $\begin{array}{l}\text { Middle tertile } \\
(n=329)\end{array}$ & $\begin{array}{l}\text { Upper tertile } \\
(n=336)\end{array}$ & \\
\hline BMI tertile range & $12.5,20.6$ & $20.7,24.3$ & $24.4,39.2$ & & $15.4,23.1$ & $23.1,27.0$ & $27.1,42.3$ & \\
\hline \multicolumn{9}{|l|}{ Maternal characteristics } \\
\hline Age (y) & $26.5(6.06)$ & $29.1(5.18)$ & $30.2(6.06)$ & $<0.0011$ & $26.3(4.5)$ & $28.0(5.3)$ & $29.7(5.0)$ & $<0.0011$ \\
\hline Height (cm) & $156.7(5.7)$ & $155.8(5.9)$ & $155.4(5.8)$ & 0.151 & $161.4(6.4)$ & $161.3(6.6)$ & $160.5(6.4)$ & 0.141 \\
\hline Weight (kg) & $45.6(4.5)$ & $54.7(5.0)$ & $67.5(8.6)$ & $<0.0011$ & $53.8(6.1)$ & $64.7(6.2)$ & $79.1(9.4)$ & $<0.0011$ \\
\hline Education (\%) & & & & 0.792 & & & & 0.372 \\
\hline low & $25(17.4)$ & $22(15.4)$ & $25(16.9)$ & & $88(26.3)$ & $83(25.2)$ & $69(20.5)$ & \\
\hline medium & $94(65.3)$ & $90(62.9)$ & $89(60.1)$ & & $214(64.1)$ & $206(62.6)$ & $223(66.4)$ & \\
\hline high & $25(17.4)$ & $31(21.7)$ & $34(23.0)$ & & $32(9.6)$ & $40(12.2)$ & $44(13.1)$ & \\
\hline Employment (\%) & & & & 0.022 & & & & 0.262 \\
\hline not working & $67(46.5)$ & $66(47.1)$ & $87(58.8)$ & & $47(14.1)$ & $50(15.2)$ & $35(10.4)$ & \\
\hline non-formal & $8(5.6)$ & $13(9.3)$ & $17(11.5)$ & & $245(73.4)$ & $237(72.0)$ & 265 (78.9) & \\
\hline formal & 69 (47.9) & $61(43.6)$ & 44 (29.7) & & $42(12.6)$ & $42(12.8)$ & $36(10.7)$ & \\
\hline Second hand smoking (\%) & $31(57.4)$ & $34(66.7)$ & $35(56.5)$ & 0.492 & & & & \\
\hline \multicolumn{9}{|l|}{ Obstetric characteristics } \\
\hline Gestational age $(w k)^{a}$ & $9.1(3.4)$ & $8.7(3.5)$ & $9.4(3.3)$ & 0.143 & $12.2(2.9)$ & $12.3(2.8)$ & $11.7(3.0)$ & 0.113 \\
\hline Gravidity (\%) & & & & $<0.0012$ & & & & $<0.0012$ \\
\hline primigravida & $67(57.8)$ & $39(34.5)$ & $34(27.0)$ & & 99 (29.6) & $80(24.3)$ & $44(13.1)$ & \\
\hline multigravida & $49(42.2)$ & $74(65.5)$ & $92(73.0)$ & & $235(70.4)$ & $249(75.7)$ & $292(86.9)$ & \\
\hline \multicolumn{9}{|l|}{ Clinical characteristics } \\
\hline Haemoglobin (g/dL) & $12.0(1.3)$ & $12.4(1.1)$ & $12.6(1.0)$ & $<0.0011$ & $10.9(1.8)$ & $11.1(1.4)$ & $11.5(1.5)$ & $<0.0011$ \\
\hline MCV below 80.0 fL (\%) & $42(29.0)$ & $27(19.0)$ & 29 (19.9) & 0.082 & & & & \\
\hline Comorbidities $^{b}$ & & & & & $56(16.8)$ & $52(15.8)$ & $46(13.7)$ & 0.532 \\
\hline \multicolumn{9}{|l|}{ Birth outcomes } \\
\hline Low birth weight (\%) & $7(6.4)$ & $5(4.5)$ & $5(4.0)$ & 0.682 & $22(8.8)$ & $20(7.7)$ & $16(6.0)$ & 0.492 \\
\hline Prematurity (\%) & $5(4.5)$ & $5(4.5)$ & $7(5.7)$ & 0.892 & $18(7.4)$ & $22(8.9)$ & $20(8.0)$ & 0.832 \\
\hline Stillbirth (\%) & $1(0.9)$ & $1(0.9)$ & $1(0.8)$ & 1.004 & $3(1.2)$ & $2(0.8)$ & $1(0.4)$ & 0.464 \\
\hline
\end{tabular}

Significant at $P$ value $<0.005 ; 1$ One-way ANOVA; 2 Chi-square; 3 Kruskal-Wallis; 4 Fisher's exact test with $N<5$

a at first ANC visit and based upon last menstrual period or ultrasound

${ }^{b}$ red blood cell affecting comorbidities including sickle cell disease, G6PD deficiency and malaria infection

\section{Anaemia and birth outcomes}

The number of women with the composite adverse birth outcomes was $28(6.1 \%)$ in Indonesia and 103 (10.9\%) in Ghana. As is presented in Table 3, anaemia was not associated with adverse birth outcomes in neither the Indonesian (adjusted OR 1.29; 95\% CI 0.35, 4.76) nor the Ghanaian (adjusted OR 1.09; 95\% CI 0.71, 1.68) cohort.

\section{Discussion}

This study showed that lower early pregnancy BMI is associated with lower haemoglobin levels and higher risk of anaemia at first antenatal care visit in Indonesian and Ghanaian women.
Estimated mean haemoglobin level in Indonesian pregnant women was $12.4 \mathrm{~g} / \mathrm{dL}$, which is slightly higher than the mean maternal haemoglobin of $11.7 \mathrm{~g} / \mathrm{dL}$ reported previously by WHO [31]. The prevalence of maternal anaemia $(10.4 \%)$ was much lower than in previous studies (prevalence estimates between 25 and 30\%) [2, 31]. This could be due to the urban setting where the study was conducted, while previous studies included rural areas data. For the Ghanaian cohort, the estimated haemoglobin mean was comparable to that previously reported in Ghanaian and Sub-Saharan African pregnant women [2, 31].

Several studies reported that lower BMI in pre- or early pregnancy is associated with anaemia in pregnancy [14, 18, 36]. However, many had methodological limitations, 
Table 2 Effect of early pregnancy weight $(\mathrm{kg})$, height $(\mathrm{m})$, and BMI $(\mathrm{kg} / \mathrm{m} 2)$ on haemoglobin concentration $(\mathrm{g} / \mathrm{dL})$ at booking with corresponding anaemia risks

\begin{tabular}{|c|c|c|c|c|c|c|c|}
\hline \multirow{2}{*}{ Linear regression } & & \multicolumn{3}{|c|}{ Indonesian cohort } & \multicolumn{3}{|c|}{ Ghanaian cohort } \\
\hline & & & & & & & \\
\hline & & Coefficient & $95 \% \mathrm{Cl}$ & P & Coefficient & $95 \% \mathrm{Cl}$ & $P$ \\
\hline \multicolumn{8}{|l|}{ Weight (kg) } \\
\hline \multirow[t]{4}{*}{ Haemoglobin (g/dL) } & Crude & 0.021 & $0.01,0.03$ & $<0.001$ & 0.017 & $0.01,0.03$ & $<0.001$ \\
\hline & Model 1 & 0.02 & $0.01,0.03$ & $<0.001$ & 0.017 & $0.01,0.03$ & $<0.001$ \\
\hline & Model 2 & 0.02 & $0.01,0.03$ & $<0.001$ & 0.017 & $0.01,0.03$ & $<0.001$ \\
\hline & Model 3 & 0.02 & $0.01,0.03$ & $<0.001$ & 0.016 & $0.01,0.02$ & $<0.001$ \\
\hline \multicolumn{8}{|l|}{ Height (cm) } \\
\hline \multirow[t]{4}{*}{ Haemoglobin $(\mathrm{g} / \mathrm{dL})$} & Crude & -0.004 & $-0.02,0.02$ & 0.71 & 0.014 & $-0.001,0.03$ & 0.07 \\
\hline & Model 1 & -0.004 & $-0.02,0.02$ & 0.67 & 0.012 & $-0.003,0.03$ & 0.13 \\
\hline & Model 2 & -0.005 & $-0.02,0.01$ & 0.62 & 0.012 & $-0.003,0.03$ & 0.13 \\
\hline & Model 3 & -0.005 & $-0.02,0.01$ & 0.61 & 0.002 & $-0.01,0.02$ & 0.79 \\
\hline \multicolumn{8}{|c|}{ Early pregnancy BMI (kg/m2) } \\
\hline \multirow[t]{4}{*}{ Haemoglobin (g/dL) } & Crude & 0.054 & $0.03,0.08$ & $<0.001$ & 0.042 & $0.02,0.06$ & $<0.001$ \\
\hline & Model 1 & 0.054 & $0.03,0.08$ & $<0.001$ & 0.042 & $0.02,0.06$ & $<0.001$ \\
\hline & Model 2 & 0.054 & $0.03,0.08$ & $<0.001$ & 0.041 & $0.02,0.06$ & $<0.001$ \\
\hline & Model 3 & 0.054 & $0.03,0.08$ & $<0.001$ & 0.044 & $0.02,0.07$ & $<0.001$ \\
\hline \multicolumn{8}{|l|}{ Logistic regression } \\
\hline & & OR & $95 \% \mathrm{Cl}$ & $P$ & OR & $95 \% \mathrm{Cl}$ & P \\
\hline \multicolumn{8}{|l|}{ Weight (kg) } \\
\hline \multirow[t]{4}{*}{ Anaemia $(<11.0 \mathrm{~g} / \mathrm{dL})$} & Crude & 0.97 & $0.94,1.00$ & 0.03 & 0.98 & $0.97,0.99$ & $<0.001$ \\
\hline & Model 1 & 0.96 & $0.93,1.00$ & 0.03 & 0.98 & $0.97,0.99$ & 0.001 \\
\hline & Model 2 & 0.96 & $0.93,1.00$ & 0.04 & 0.98 & $0.97,0.99$ & 0.001 \\
\hline & Model 3 & 0.96 & $0.93,1.00$ & 0.03 & 0.98 & $0.97,0.99$ & 0.002 \\
\hline \multicolumn{8}{|l|}{ Height (cm) } \\
\hline \multirow[t]{4}{*}{ Anaemia $(<11.0 \mathrm{~g} / \mathrm{dL})$} & Crude & 1.04 & $0.99,1.10$ & 0.13 & 0.99 & $0.97,1.01$ & 0.53 \\
\hline & Model 1 & 1.05 & $0.99,1.11$ & 0.09 & 1 & $0.98,1.02$ & 0.75 \\
\hline & Model 2 & 1.05 & $0.99,1.11$ & 0.09 & 1 & $0.98,1.02$ & 0.75 \\
\hline & Model 3 & 1.05 & $0.99,1.11$ & 0.1 & 1.01 & $0.99,1.03$ & 0.5 \\
\hline \multicolumn{8}{|c|}{ Early pregnancy BMI (kg/m2) } \\
\hline \multirow[t]{4}{*}{ Anaemia $(<11.0 \mathrm{~g} / \mathrm{dL})$} & Crude & 0.89 & $0.82,0.97$ & 0.01 & 0.95 & $0.92,0.97$ & $<0.001$ \\
\hline & Model 1 & 0.88 & $0.81,0.97$ & 0.01 & 0.95 & $0.92,0.98$ & 0.001 \\
\hline & Model 2 & 0.88 & $0.80,0.97$ & 0.01 & 0.95 & $0.92,0.98$ & 0.001 \\
\hline & Model 3 & 0.88 & $0.81,0.97$ & 0.01 & 0.95 & $0.92,0.98$ & $<0.001$ \\
\hline
\end{tabular}

OR odds ratio

Results are expressed as linear regression coefficients of haemoglobin concentration in $\mathrm{g} / \mathrm{dL}$ or logistic regression coefficients of maternal anemia for every 1 unit increase in exposures

Model 1 is adjusted for maternal age, education level and employment status

Model 2 is adjusted as for model 1 and for gravidity

Model 3 is adjusted as for model 2 and for secondhand smoking exposure in Indonesian cohort or anaemia-associated-comorbidities in Ghanaian cohort

including lack of adjustment for gestational age and differences in anaemia cut-off levels and gestational age at blood withdrawal $[25,37,38]$. These issues were addressed specifically in our study.

In both cohorts, higher early pregnancy weight was related to higher haemoglobin levels and lower risk for anaemia. Low early pregnancy weight or BMI may be a reflection of poor nutrition intake, including the intake of various micronutrients that are essential for haematopoiesis [1]. Furthermore, low weight or BMI could be a result of chronic illness, such as tuberculosis or parasitic infections, which consequently lead to anaemia $[8,25]$. 

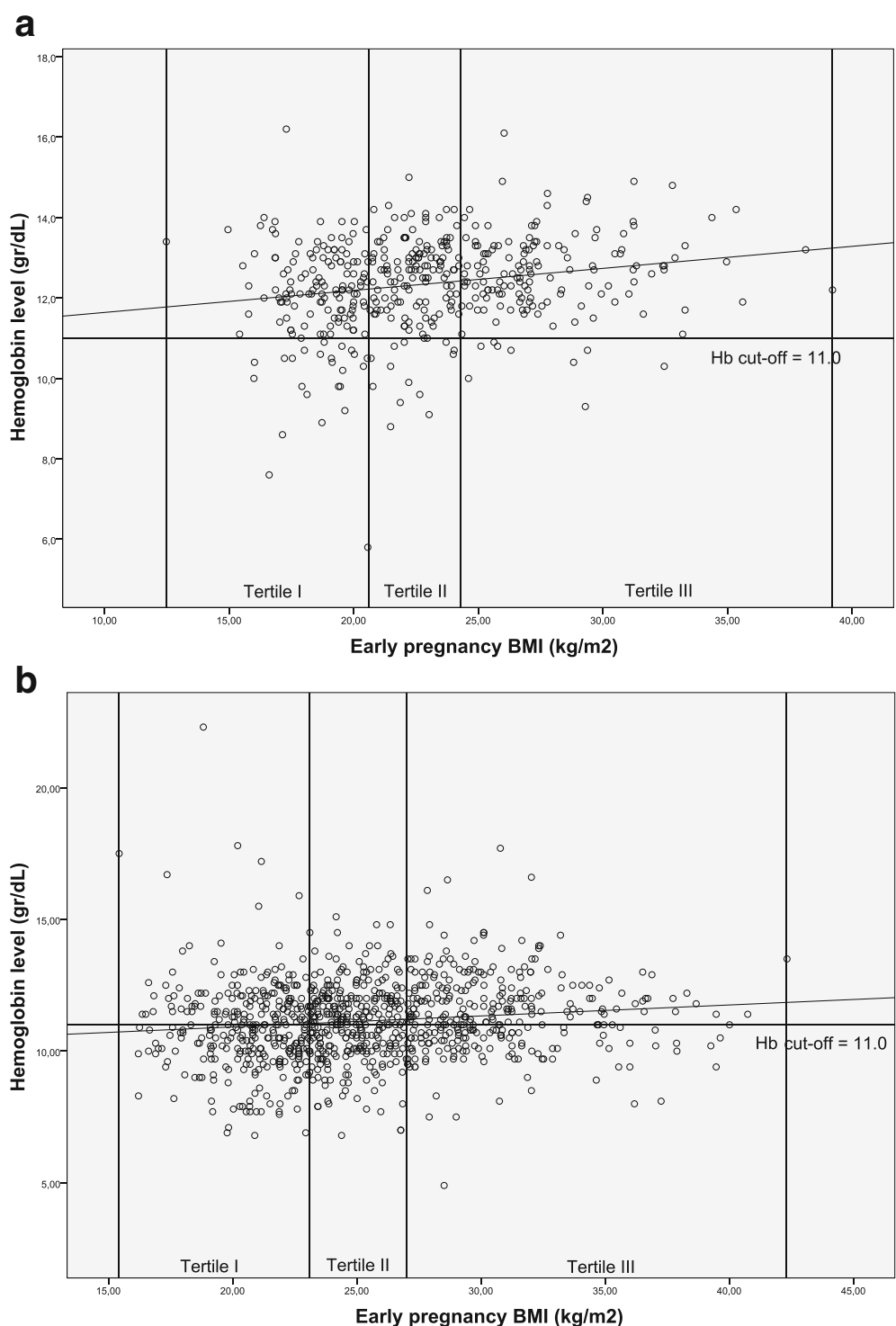

Fig. $\mathbf{1}$ a and $\mathbf{b}$ Scatterplots of Indonesian and Ghanaian women divided into early pregnancy BMI groups by haemoglobin level; a: Indonesian cohort. b Ghanaian cohort

These conditions are still the major health problems globally and are often under-diagnosed [39-41].

Previous studies observed an association between anaemia in pregnancy and an increased risk of maternal mortality [11],adverse maternal outcomes including quality of life, and infant outcomes $[1,3]$. In this study, we did not observe an association between early pregnancy anaemia and a composite of birth outcomes. We did not put $\mathrm{BMI}$ in the regression model because we considered BMI a mediator rather than a confounder. The absence of an association may be explained by the relatively low incidence of adverse events in both cohorts.

The high anaemia prevalence in Sub-Saharan Africa is attributed to factors such as poor nutrition, haemoglobinopathies, as sickle cell disease, or parasitic infections including malaria [2, 42]. Several studies suggest to consider lower haemoglobin cut-off values for diagnosis of anaemia in Sub-Saharan African populations $[42,43]$, as using universal cut-off for anaemia could result in a high number of anaemia cases not accompanied with significant clinical symptoms or increased risk of adverse pregnancy outcomes [12].

Both in Indonesia and Ghana, anaemia screening and treatment during antenatal care is recommended by (inter)national guidelines [44-46]. Potential intrapartum and postpartum complications associated with low haemoglobin levels, particularly postpartum haemorrhage, still in the top three causes of maternal mortality in Sub-Saharan Africa 
Table 3 Crude and adjusted risks for the composite adverse birth outcomes according to maternal anaemia status at first booking

\begin{tabular}{|c|c|c|c|c|c|c|c|}
\hline \multirow[t]{2}{*}{ Logistic regression } & & \multicolumn{3}{|c|}{ Indonesian cohort } & \multicolumn{3}{|c|}{ Ghanaian cohort } \\
\hline & & $\mathrm{OR}$ & $95 \% \mathrm{Cl}$ & $P$ & $\mathrm{OR}$ & $95 \% \mathrm{C}$ & P \\
\hline \multicolumn{8}{|l|}{ Haemoglobin (g/dL) } \\
\hline \multirow[t]{4}{*}{ Adverse birth outcomes ${ }^{a}$} & Crude & 0.91 & $0.65,1.27$ & 0.58 & 0.97 & $0.85,1.11$ & 0.69 \\
\hline & Model 1 & 0.91 & $0.66,1.27$ & 0.59 & 0.97 & $0.85,1.12$ & 0.71 \\
\hline & Model 2 & 0.9 & $0.65,1.26$ & 0.54 & 0.98 & $0.85,1.12$ & 0.71 \\
\hline & Model 3 & 0.9 & $0.65,1.25$ & 0.53 & 0.98 & $0.85,1.12$ & 0.73 \\
\hline \multicolumn{8}{|l|}{ Anaemia (< 11.0 g/dL) } \\
\hline \multirow[t]{4}{*}{ Adverse birth outcomes ${ }^{a}$} & Crude & 1.4 & $0.40,4.93$ & 0.61 & 1.09 & $0.72,1.67$ & 0.68 \\
\hline & Model 1 & 1.26 & $0.35,4.57$ & 0.72 & 1.1 & $0.72,1.69$ & 0.66 \\
\hline & Model 2 & 1.3 & $0.36,4.71$ & 0.7 & 1.1 & $0.72,1.69$ & 0.66 \\
\hline & Model 3 & 1.29 & $0.35,4.76$ & 0.7 & 1.08 & $0.70,1.69$ & 0.71 \\
\hline
\end{tabular}

OR, odds ratio adverse birth outcomes included low birth weight, prematurity, and stillbirthResults are expressed as logistic regression coefficients of adverse birth outcomes with exposure categories

Model 1 is adjusted for maternal age, education level and employment status

Model 2 is adjusted as for model 1 and for gravidity

Model 3 is adjusted as for model 2 and for secondhand smoking exposure in Indonesian cohort or anemia-associated-comorbidities in Ghanaian cohort

$[10,11,47,48]$, justify this recommendation. The extent to which anaemia screening is implemented in routine antenatal care, varies between countries [49]. Given the high prevalence of anaemia during pregnancy, intensifying routine screening (especially in the third trimester) and early initiation of treatment when routine supplementation of iron did not suffice, would be recommended.

Our study had several strengths. First, both cohorts have a prospective design and are conducted in similar time periods. This enables direct comparison between the two populations and minimizes possible cohort effect. Secondly, the strength of this study lies in its novelty. To the best of our knowledge, this is the first study which (simultaneously) investigated the association between early pregnancy BMI and maternal anaemia in Southeast Asia and Sub-Saharan Africa. These are the regions of the world with the highest prevalence of anaemia in pregnancy and the greatest anaemia related burden of disease [2, 3, 31]. The two cohorts had used similar terms of conduct and outcome measurement and had both a favourable low prevalence of red blood cell-affecting morbidities. Both cohorts also complemented each other in terms of subjects' characteristics, which enabled comparison between the two settings and exploration of additional hypotheses. For example the influence of haemoglobin-affecting pathologies and secondhand smoking in the relation between women's BMI and anaemia. In Jakarta, a malaria non-endemic area, malaria prevalence and haemoglobinopathies occurrence were very low $[50,51]$ in contrast to prevalence estimates in Accra, Ghana [52, 53]. Rate of second hand smoking exposure, on the other hand, are very low in Ghana (0.3\%) compared to in Indonesia [28]. In addition, the characteristics of the cohort population support the generalisation of our findings to other urban low resource settings.

Certain points need to be considered in the interpretation of these findings. First, pre-pregnancy weight was asked to Indonesian women retrospectively and used as a proxy for early pregnancy weight. Consequently, inaccuracies may exist. Yet, when women's pre-pregnancy weight was compared with their measured weight at antenatal booking, we found that they were highly correlated ( $R$ square $>0.85$, data not shown). Therefore, pre-pregnancy weight was considered suitable as proxy for early pregnancy weight. Secondly, differences between Ghanaian and Indonesian women might exist regarding (gestational) age during enrolment and reported pre-existing hypertension. However, possible differences are minimal and were therefore considered inconsequential.

\section{Conclusions}

In summary, in pregnant women from urban settings in Indonesia and Ghana, low early pregnancy BMI relates to an increased risk for anaemia at first antenatal care visit. Therefore, health providers should consider initiating early anaemia screening or treatment. Anaemia prevalence in Indonesians is notably lower than previously reported, whilst nearly four in ten Ghanaian women are anaemic according to international standards. Contrary to previous studies, in both cohorts anaemia was not associated with adverse birth outcomes.

\section{Additional file}

Additional file 1: Table S1. Missing values upon baseline characteristics of the study populations. The supplementary table shows the incidence of missing data for each baseline characteristic. (XLSX 8 kb) 


\section{Abbreviations}

ANC: Antenatal care; BMl: Body mass index; G6PD: Glucose-6-phosphate dehydrogenase; GHS-ERC: Ghana Health Services Ethical Review Committee; LMIC's: Low- and middle income countries; WHO: World Health Organization

\section{Acknowledgements}

We gratefully acknowledge study participation of the pregnant women enrolling in these studies and staff of participating health facilities. We are appreciative of the research assistants who conducted the interviews, data collection, and data entry.

\section{Funding}

The establishment of the Indonesian and Ghanaian cohorts was supported by the UMC Utrecht Global Health PhD fellowship. The funding body did not have a role in design of the study and collection, analysis, interpretation of data or in writing the manuscript.

\section{Availability of data and materials}

The datasets used and/or analysed during the current study are available from the corresponding author on reasonable request.

\section{Authors' contributions}

MM, AIS, CSPMU and JLB conceived and designed the study. Primary responsibility for obtaining ethical approval obtainment, study design and acquisition of data for the Ghanaian study were JLB and EA and AIS and CSPMU for the Indonesian study. DA, MB, DEG and KK-G substantially contributed to the design of the Ghanaian and Indonesian cohorts. Analysis and writing of the first draft of the manuscript was performed by MM, supported by AIS, CSPMU and JLB. DA, MB, DEG and KKG substantially commented on and provided revisions on the manuscript. All authors approved the final version for publication.

\section{Ethics approval and consent to participate}

For the Indonesian cohort ethical approval was granted by the Institutional Review Board of Budi Kemuliaan Hospital. For the Ghanaian study population approval was obtained from Ghana Health Services Ethical Review Committee (GHS-ERC 07-9-11). In both cohorts, participating women provided written or thumbprint informed consent prior to study enrolment.

\section{Consent for publication}

Not applicable.

\section{Competing interests}

The authors declare that they have no competing interests.

\section{Publisher's Note}

Springer Nature remains neutral with regard to jurisdictional claims in published maps and institutional affiliations.

\section{Author details}

${ }^{1}$ Julius Global Health, Julius Center for Health Sciences and Primary Care, University Medical Center Utrecht, Utrecht, The Netherlands. ${ }^{2}$ Budi Kemuliaan Hospital, Jakarta, Indonesia. ${ }^{3}$ Ghana Health Service, Accra, Ghana. ${ }^{4}$ Division of Epidemiology and Biostatistics, School of Public Health, Faculty of Health Sciences, University of the Witwatersrand, Johannesburg, South Africa.

Received: 10 November 2017 Accepted: 12 June 2018

Published online: 13 July 2018

\section{References}

1. Balarajan Y, Ramakrishnan U, Özaltin E, et al. Anaemia in low-income and middle-income countries. Lancet. 2011;378:2123-35.

2. Stevens GA, Finucane MM, De-Regil LM, et al. Global, regional, and national trends in haemoglobin concentration and prevalence of total and severe anaemia in children and pregnant and non-pregnant women for 19952011: a systematic analysis of population-representative data. Lancet Glob Heal. 2013;1:16-25.

3. Rahman M, Abe SK, Rahman S, et al. Maternal anemia and risk of adverse birth and health outcomes in low- and middle-income countries : systematic review and meta-analysis. Am J Clin Nutr. 2016;103:495-504.
4. Glover-Amengor M, Owusu WB, Akanmori B. Determinants of anaemia in pregnancy in Sekyere West District, Ghana. Ghana Med J. 2005;39:102-7.

5. Chowdhury HA, Ahmed KR, Jebunessa F, Akter J, Hossain S, Shahjahan M. Factors associated with maternal anaemia among pregnant women in Dhaka city. BMC Womens Health. 2015;15:77.

6. Levy A, Fraser D, Katz M, Mazor M, Sheiner E. Maternal anemia during pregnancy is an independent risk factor for low birthweight and preterm delivery. Eur J Obstet Gynecol Reprod Biol. 2005;122:182-6.

7. Haniff J, Das A, Onn LT, et al. Anemia in pregnancy in Malaysia: a crosssectional survey. Asia Pac J Clin Nutr. 2007;16:527-36.

8. Gedefaw L, Ayele A, Asres Y, Mossie A. Anemia and associated factors among pregnant women attending antenatal care clinic in Wolayita Sodo town, Southern Ethiopia. Ethiop J Health Sci. 2015;25:155-62.

9. Karaoglu L, Pehlivan E, Egri M, et al. The prevalence of nutritional anemia in pregnancy in an east Anatolian province, Turkey. BMC Public Health. 2010; 10:329.

10. Haider B, Olofin I, Wang M, Spiegelman D, Ezzati M, Fawzi W. Anaemia, prenatal iron use, and risk of adverse pregnancy outcomes: systematic review and meta-analysis. Br Med J. 2013;3443:1-19.

11. Daru J, Zamora J, Fernández-Félix BM, et al. Risk of maternal mortality in women with severe anaemia during pregnancy and post partum: a multilevel analysis. Lancet Glob Health 2018; published online March 20. https://doi.org/10.1016/\$2214-109X(18)30078-0.

12. World Health Organisation. Nutrition for health and development: a global agenda for combating malnutrition. 2000.

13. Stoltzfus R, Mullany L, Black R. Iron deficiency anaemia. In: Comparative Quantification of Health Risks. 2004. p. 163-209.

14. Liu X, Du J, Wang G, Chen Z, Wang W, Xi Q. Effect of pre-pregnancy body mass index on adverse pregnancy outcome in north of China. Arch Gynecol Obstet. 2011:283:65-70.

15. Pan $Y$, Zhang $S$, Wang $Q$, et al. Investigating the association between prepregnancy body mass index and adverse pregnancy outcomes: a large cohort study of 536098 Chinese pregnant women in rural China. BMJ Open. 2016;6:e011227.

16. Schummers L, Hutcheon JA, Bodnar LM, Lieberman E, Himes KP. Risk of adverse pregnancy outcomes by Prepregnancy body mass index. Obstet Gynecol. 2015;125:133-43.

17. Bhattacharya S, Campbell DM, Liston WA, Bhattacharya S. Effect of body mass index on pregnancy outcomes in nulliparous women delivering singleton babies. BMC Public Health. 2007;7:168.

18. Sebire NJ, Jolly M, Harris J, Regan L, Robinson S. Is maternal underweight really a risk factor for adverse pregnancy outcome? A population-based study in London. Br J Obstet Gynaecol. 2001;108:61-6.

19. Han Z, Mulla S, Beyene J, Liao G, McDonald SD. Maternal underweight and the risk of preterm birth and low birth weight: a systematic review and meta-analyses. Int J Epidemiol. 2011;40:65-101.

20. Ehrenberg HM, Dierker L, Milluzzi C, Mercer BM. Low maternal weight, failure to thrive in pregnancy, and adverse pregnancy outcomes. Am J Obstet Gynecol. 2003:189:1726-30.

21. Jain D, Khuteta R, Chaturvedi V, Khuteta S. Effect of body mass index on pregnancy outcomes in nulliparous women delivering singleton babies: observational study. J Obstet Gynecol India. 2012;62:429-31.

22. Triunfo S, Lanzone A. Impact of overweight and obesity on obstetric outcomes. J Endocrinol Investig. 2014;37:323-9.

23. Savitri Al, Zuithoff $\mathrm{P}$, Browne $\mathrm{J}$, et al. Does pre-pregnancy BMI determine blood pressure during pregnancy? A prospective cohort study. BMJ Open. 2016;6:e011626.

24. Yu CKH, Teoh TG, Robinson S. Obesity in pregnancy. BJOG An Int J Obstet Gynaecol. 2006;113:1117-25.

25. Sifakis S, Pharmakides G. Anemia in pregnancy. Ann N Y Acad Sci. 2000;900: 125-36.

26. Koudijs HM, Savitri Al, Browne JL, et al. Hyperemesis gravidarum and placental dysfunction disorders. BMC Pregnancy Childbirth. 2016;16:374.

27. Van Der Linden ELL, Browne JLL, Vissers KMM, et al. Maternal body mass index and adverse pregnancy outcomes: a ghanaian cohort study. Obes (Silver Spring). 2016:24:215-22

28. Owusu-Dabo E, Lewis S, McNeill A, Gilmore A, Britton J. Smoking uptake and prevalence in Ghana. Tob Control. 2009:18:365-70.

29. World Health Organization. Haemoglobin concentrations for the diagnosis of anaemia and assessment of severity. 2011.

30. World Health Organization. ICD-10 transition. Fam Pract Manag. 2011;18:39. 
31. World Health Organization. The global prevalence of anaemia in 2011: WHO Rep; 2011. p. 48.

32. Lundström U. Iron deficiency anaemia. Gut. 1994;35:864-5.

33. World Health Organization. Public health appropriate body-mass index for Asian populations and its implications for policy and intervention strategies. Public Health. 2004:363:157-63.

34. Shiwaku K, Anuurad E, Enkhmaa B, Kitajima K, Yamane Y. Appropriate BMI for Asian populations. Lancet. 2004;363:1077.

35. Von EE, Altman DG, Egger M, et al. Strengthening the reporting of observational studies in epidemiology (STROBE). Epidemiology. 2007;18:805-35.

36. Agrawal S, Singh A. Obesity or underweigh: what is worse in pregnancy? Obstet Gynecol India. 2015;66:448-52.

37. Milman N, Byg K-E, Agger A. Hemoglobin and erythrocyte indices during normal pregnancy and postpartum in 206 women with and without iron supplementation. Acta Obstet Gynecol Scand. 2000;79:89-98.

38. Tomashek KM, Ananth CV, Cogswell ME. Risk of stillbirth in relation to maternal haemoglobin concentration during pregnancy. Matern Child Nutr. 2006;2:19-28.

39. World Health Organization, Regional Office for South-East Asia. 11 health questions about the 11 SEAR countries. Department of Health Systems Development, WHO Regional Office for South-East Asia; 2007. http://www. who.int/iris/handle/10665/204719.

40. Gupta I, Guin P. Communicable diseases in the South-East Asia region of the World Health Organization: towards a more effective response. Bull World Health Organ. 2010;88:199-205.

41. Black RE, Victora CG, Walker SP, et al. Maternal and child undernutrition and overweight in low-income and middle-income countries. Lancet. 2013;382: 427-51.

42. Karita E, Ketter N, Price MA, et al. CLSI-derived hematology and biochemistry reference intervals for healthy adults in eastern and southern Africa. PLoS One. 2009;4. https://doi.org/10.1371/journal.pone.0004401.

43. Dosoo DK, Kayan K, Adu-Gyasi D, et al. Haematological and biochemical reference values for healthy adults in the Middle Belt of Ghana. PLoS One. 2012;7:1-9.

44. Mcdonagh M, Cantor A, Bougatsos C, Dana T, Blazina I. Routine iron supplementation and screening for iron deficiency anemia in pregnant women: a systematic review to update the U.S. preventive services task force. Theatr Rec. 2015. https://doi.org/10.7326/M14-2932.

45. Lincetto O, Mothebesoane-anoh S, Gomez P, Munjanja S. Antenatal care: opprotunities for Africa's newborns. Int J Sci Technol Res. 2013;2:51-62.

46. World Health Organization. WHO recommendations on antenatal care for a positive pregnancy experience. Geneva: WHO; 2016. p. 152.

47. Gulmezoglu AM, Souza JP, Mathai M. WHO recommendations for the prevention and treatment of postpartum haemorrhage; 2012. https://doi. org/10.1016/j.jigo.2013.06.024.

48. Mpemba F, Kampo S, Zhang X. Towards 2015: post-partum haemorrhage in sub-Saharan Africa still on the rise. J Clin Nurs. 2014;23:774-83.

49. Amoakoh-Coleman M, Agyepong IA, Zuithoff NPA, et al. Client factors affect provider adherence to clinical guidelines during first antenatal care. PLoS One. 2016:11:e0157542.

50. Banbang Hartono, Bob Susilo Kusumobro to, Sugito, Sunaryadi, Nuning Kurniasih, Boga Hardana, Evida Manulang M. Syahrul Anam D. Profil kesehatan Indonesia 2005. Jakarta: Dep Kesehat Rl; 2007. p. 160.

51. Elyazar IR, Hay SIBJ. Malaria distribution, prevalence, drug resistance and control in Indonesia. Adv Parasitol. 2011:74:41-175.

52. WHO-TIF. Management of haemoglobin disorders: report of a Joint WHOTIF Meeting. 2007.

53. JSI Research \& Training Institute. Report of the Ghana urban malaria study Accra: JSI Research and Training Institute, Inc.; 2013. https://www.jsi.com/ Independent/Docs/GhanaUrbanMalariaStudy.pdf.

Ready to submit your research? Choose BMC and benefit from:

- fast, convenient online submission

- thorough peer review by experienced researchers in your field

- rapid publication on acceptance

- support for research data, including large and complex data types

- gold Open Access which fosters wider collaboration and increased citations

- maximum visibility for your research: over $100 \mathrm{M}$ website views per year

At BMC, research is always in progress.

Learn more biomedcentral.com/submissions 